\title{
Some investigations on Cox's disease in Cox's Orange Pippin apple trees, grafted on dwarfing rootstock M IX
}

\author{
B. W. Veen and J. Th. Locher
}

Institute for Biological and Chemical Research on Field Crops and Herbage (IBS), Wageningen, the Netherlands

Received: 7 September 1972

\section{Summary}

Young Cox's Orange Pippin apple trees grafted on the dwarfing rootstock M IX often show the so-called Cox's disease. Trees suffering from Cox's disease show a sudden mortality in the periphery of the root system. This is regarded as the primary cause of other severe above-ground symptoms, like midshoot leaf fall and - in the next year less flowering and fruit set.

To study the cause of Cox's disease, which in earlier work is considered to be a physiological one, several experiments have been performed with two-year old Cox's/M IX and Cox's/M II combinations grown in containers.

In $197040 \mathrm{Cox}$ 's/M IX graft combinations were set up on sand and 40 on water culture to study the effect of different carbohydrate levels on the occurrence of Cox's 'disease. A number of trees was grown under plastic gauze to diminish the light intensity and, with it, the carbohydrate level. Deprivation of nitrogen raised the carbohydrate level in another group.

In 1971 the insensitive Cox's/M II and the sensitive Cox's/M IX combinations, grown on sand and on water culture, were compared. The transport of ${ }^{14} \mathrm{C}$-labeled carbohydrates was studied, as well as differences in growth and morphology of the two combinations.

On sand culture Cox's disease occurred in 1970 in a number of trees in the control group and the group grown under low light intensity. In 1971 no Cox's disease was observed in sand culture trees.

The trees on water culture showed Cox's disease-like root mortality without the aboveground symptoms. The latter may be attributed to the fact that shoot growth had already stopped.

This root mortality on water culture was not caused by a lack of carbohydrates. No irregularity in the carbohydrate transport through the graft union could be observed in Cox's/M IX or in Cox's/M II trees. The same applied to the healthy trees on sand culture. Differences in root morphology between 1) Cox's/M II; 2) Cox's/M IX (both on sand culture); 3) trees on water culture coincided with differences in susceptibility to root mortality. This, together with data from the literature, leads to the suggestion that disturbance in the hormonal equilibrium in the root system is a possible cause of Cox's disease. 


\section{Introduction}

The dwarfing rootstock M IX grafted with Cox's Orange Pippin, used in modern horticulture for its precocity and denser planting possibilities, has the drawback that specific growth disorders occur in a number of trees, which are called Cox's disease (Oud et al., 1967; Visser, 1968).

Cox's disease is characterized by the following symptoms. In August and September the appearance of necrotic spots on the leaves of the apple trees is followed by midshoot leafdrop. The lower and spur leaves show a reddening caused by high sugar content of the leaves; the top leaves become yellowish and show water stress symptoms. These summer symptoms occur when the main shoots have mostly completed growth.

Accompanying these symptoms a change occurs in the mineral composition of the whole tree. Besides nitrate and phosphate, especially the calcium and magnesium contents of the leaves decrease, as has been measured by Visser (1968). In the root system mainly the nitrate and phosphate contents decrease. The potassium content of the leaves and the calcium, magnesium and potassium contents of the roots are not much affected. The sugar content of both leaves and roots is enhanced.

As a result of these summer symptoms the buds show a delayed outgrowth the next spring, while many buds do not develop. The new shoots are smaller and have yellowish leaves. Fruit set is diminished.

Cox's disease is not restricted to special trees. This means that effects of environment, such as soil, can only be of secondary importance. The same holds for climatic effects. Cox's disease occurs much more in one year than in another, but there is no clear relation between this occurrence and climatic factors. The cause of Cox's disease seems to be a physiological one.

Visser (1968) described root systems of trees with and without Cox's disease. In the former he observed a large number of dead roots, especially in the periphery of the root system.

Evidence that a malfunctioning root system is not the result, but the cause of the overground Cox's disease symptoms are supported by experiments of Visser et al. (1971). They found that the change in sugar content and mineral composition in diseased trees is a general effect of a poor root system.

There are some factors affecting the occurrence of Cox's disease:

1. Removal of growing apples from the trees increases the sensitivity to Cox's disease;

2. Ringing the stem up to about half its girth results in less Cox's disease (Oud, 1968b). This, in combination with Cox's disease occurring about the time when the shoot growth rate is decreasing, could possibly mean that disappearance of the sinks for carbohydrates and the subsequent enhancement of the carbohydrate transport to the roots leads to a poorly functioning root system. The effect of the partial ring in the bark could then be considered as a barrier for carbohydrate transport to the root system.

Inconsistent with this opinion is the fact mentioned by Oud (1968b) that a new thing should be applied under the old one, when the oud bark ring is overgrown and has lost its function. If a ring should act as a barrier, its effect would be independent of its position in respect to the overgrown ring.

Secondly, root dying caused by a too high sugar level is unusual in plant physiology.

Another hypothesis (Oud, 1968a, 1968b) suggested that a lack of carbohydrates causes root dying. This lack should be caused by a block in the carbohydrate transport, the functioning of which should be regulated by hormones. Removal of growing fruit and stopping shoot growth are attended by alterations in the hormonal balance, because 
auxin production centres are removed and this could block carbohydrate transport through the graft. Applying a partial bark ring should cause new hormone production and re-establish the phloem transport.

An indication for such a mechanism was given by Dickson and Samuels (1956), who concluded from their experiments on ${ }^{32} \mathrm{P}$ transport that the dwarfing effect of an interstock or an inverted ring of bark might be caused by checking the flow of organic nutrients to the roots.

That phloem transport through a graft can be hormonally controlled is for instance concluded by de Stigter $(1961,1971)$, in the graft combination of Cucumis melo L. or Cucumis sativus $\mathbf{L}$. on Cucurbita ficifolia Bouch.

This hypothesis would explain the inducing effect of fruit removal on Cox's disease and the occurrence of Cox's disease by the time the shoots are beginning to stop growth. It would also explain why a new ring should be applied below the old one to give the most favourable effect against Cox's disease.

Both points of view assign an important role to carbohydrates with regard to Cox's disease. Therefore in 1970 experiments were set up to grow Cox's/M IX trees with different internal carbohydrate levels and to study their effects on growth, mineral and sugar content of root and shoot and on the sensitivity of the trees to Cox's disease. Also the possible effects of partial bark ringing were examined.

In 1971 the graft combination Cox's/M IX which is sensitive to Cox's disease was compared with the not sensitive Cox's/M II combination with regard to growth, morphology and transport of carbohydrates through the graft.

\section{Materials and methods}

\section{The 1970 experiments}

The experiments of 1970 were carried out on two-year old Cox's Orange Pippin trees grafted on M IX rootstocks. To keep the trees under more or less controlled conditions, they were grown on transparent perspex containers filled with coarse sand (sand culture) or with Hoagland nutrient solution (water culture). Both groups consisted of 40 trees; they were grown in the open.

All the containers were shielded from the light by jackets made of white (outside) and black (inside) plastic filled with isolating material to prevent the temperature in the containers rising too high on sunny days.

The sand culture trees were provided with nutrient solution that ran through a rubber tube system after being pumped up to a fixed level. The tube system had a dripping nozzle above each container. Excess solution escaped from the containers through a hole near the bottom. A layer of gravel on the bottom prevented the sand from being washed away. In case of the water culture trees the oxygen supply of the roots is critical, so that vigorous aeration was necessary.

The sand culture trees were planted in the containers in the first half of April, the water culture trees at the end of April. At harvest time, at the end of September, weights of new-grown roots and shoots, and their mineral and sugar contents were measured.

From mid-June the following treatments were applied to the sand culture and the water culture trees:

1. Ten trees were provided with nutrient solution in which $\mathrm{NO}_{3}^{-}$was replaced by $\mathrm{Cl}^{-}$ (-N group). 
2. Ten trees were shaded to about $40 \%$ of the light by cages of green plastic gauze (-L group).

3. From ten trees the root function was inhibited by stopping the aeration (water culture -A group) or by raising the water level (sand culture -A group).

4. The ten remaining control trees of each group were not subjected to any of these special treatments (C group).

5. Five trees of each group of ten trees were provided with a ring around half the girth of the stem.

Growth measurements were performed on all trees, first twice, later once a week. Shoot growth was measured on three fast-growing upper shoots and on two lower shoots, whose growth was somewhat less.

Root growth of the sand culture trees was measured on the extension roots that appeared on the outside of the sand column and remained visible when growing along the inside of the perspex wall. Root growth of the water culture trees was measured on part of the root system that was kept in place close to the perspex container wall by a piece of plastic gauze that was pressed against the container wall with two bent plastic rods.

In 1970 the $\mathrm{K}^{+}, \mathrm{Ca}^{++}$and $\mathrm{NO}_{3}^{-}$uptake of the trees growing on water culture was determined regularly.

\section{The 1971 experiments}

At the beginning of April 1971 the following trees were planted:

1. On sand culture with normal nutrition during the whole season: $20 \mathrm{Cox}$ 's/M II and 40 Cox's/M IX.

2. On water culture with normal nutrition during the whole season: 5 Cox's/M IX.

3. On water culture with substitution of $\mathrm{NO}_{3}^{-}$by $\mathrm{Cl}^{-}$since July: $10 \mathrm{Cox}$ 's/M IX and 5 Cox's/M II.

During the summer carbohydrate transport through the graft of a number of trees was studied. Therefore the crown of a tree was covered with a large 'Melinex' bag being impermeable to $\mathrm{CO}_{2}$. The bag was sealed air-tight around the stem. $100 \mu \mathrm{Ci}^{14} \mathrm{CO}_{2}$ was circulated for one hour through the bag. The transport of ${ }^{14} \mathrm{C}$ sugars was studied as follows. About 7 and 24 hours after the beginning of the experiment a vertical row of little bark disks (diam. $4 \mathrm{~mm}$ ) was punched out of the stem by a cork borer. The disks were punched from $16 \mathrm{~cm}$ above to $16 \mathrm{~cm}$ below the graft union. The distance between two punches was $5 \mathrm{~cm}$, but at the graft union three punches with a distance of $1 \mathrm{~cm}$ were taken.

The bark disks were burnt in closed scintillation flasks (Wegner and Winkelmann, 1970 ) in which $1 \mathrm{ml}$ fenethylamine was pipetted to absorb the ${ }^{14} \mathrm{CO}_{2}$. After $10 \mathrm{ml}$ scintillation liquid (Bruno and Christian, 1961) were added the amount of ${ }^{14} \mathrm{C}$ was determined in a liquid scintillation counter. In addition autoradiographs were made of parts of the root systems.

Growth of shoots and roots of four Cox's/M II and four Cox's/M IX trees was regularly measured. At the end of October the trees which were not used for the ${ }^{14} \mathrm{C}$ experiments were harvested. The weights of the new-grown roots and shoots as well as the root morphology of Cox's/M IX and Cox's/M II were compared. 


\section{Results}

The effect of the different treatments on growth of Cox's/M IX trees (1970 experiments)

Shoot growth. In the course of the season there was a gradual decrease of the normal shoot growth rate of the trees grown on sand culture. Fig. 1 shows the same for the 1971 experiments. Compared with the sand culture trees the shoot growth rate of the water culture trees was markedly less, especially in the first half of the summer.

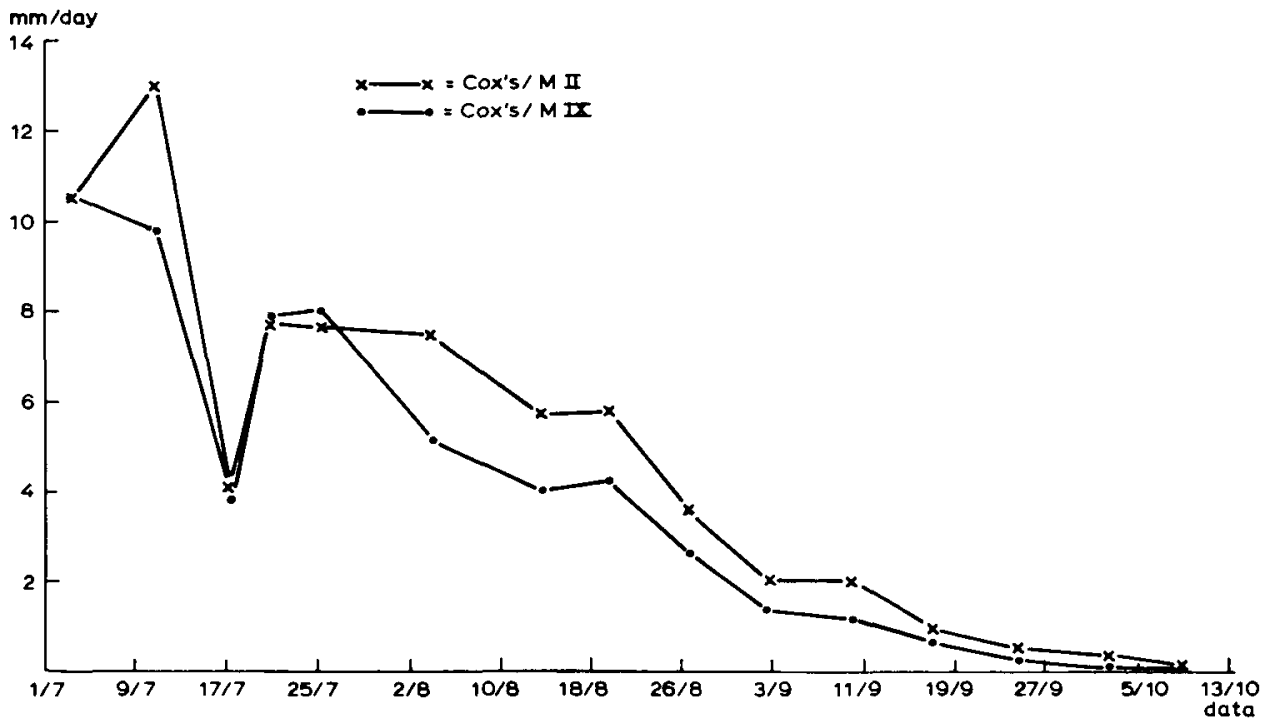

Fig. 1. Shoot growth rate of sand culture trees (1971).

Root growth. Two types of growing roots are present on Cox's trees:

1. Long white extension roots with a diameter of about $1.5 \mathrm{~mm}$ and a maximum length of about $60 \mathrm{~cm}$.

2. Short translucent spur rootlets with a diameter of about $0.3 \mathrm{~mm}$, branching in great numbers from the newly grown extension roots, especially in the region near the stem where they form a dense network.

Especially the extension roots were visible at the container wall and their growth has been measured.

The normal root growth rate measured on the extension roots was rather stable during the growing season with variations due to weather influences. The water culture trees showed a higher root growth rate of the extension roots than the sand culture trees, but far less root branching.

Applying a partial bark ring did not clearly affect shoot nor root growth rate in any of the sand and water culture trees. Lack of aeration resulted in all cases in a quick almost complete dying of the root system and consequently in a stop of shoot growth followed by leaf fall. The heavy effects of this treatment would overshadow possible Cox's disease effects. 


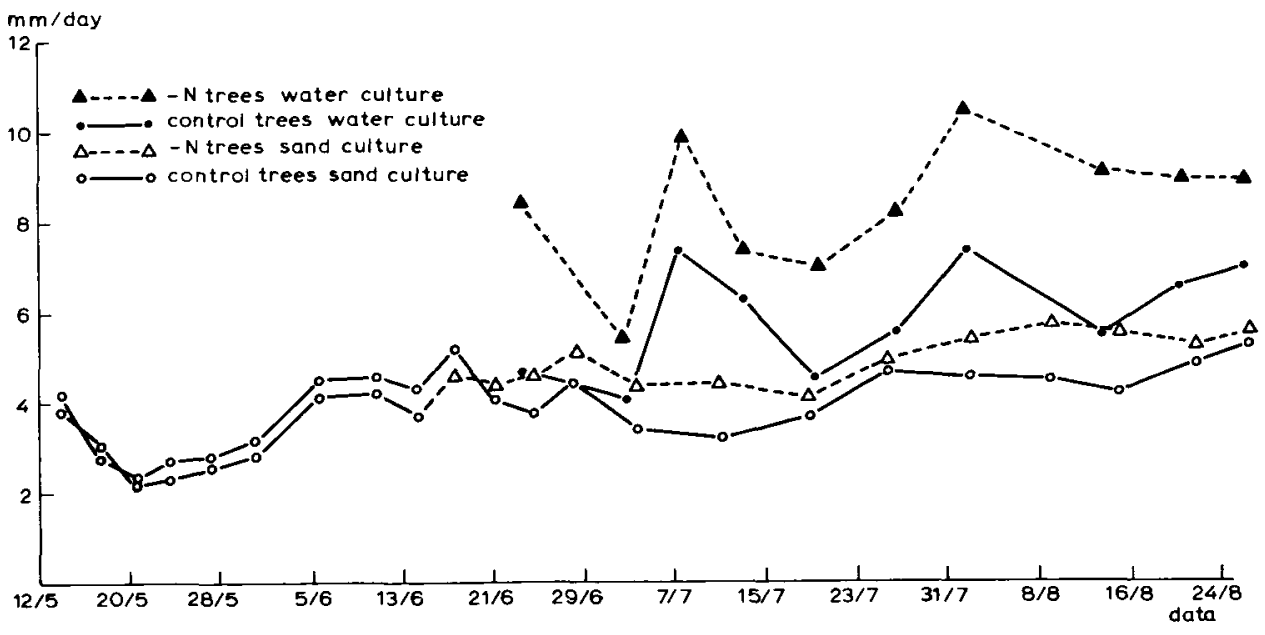

Fig. 2. The influence of nitrogen deprivation on growth of the extension roots of water and sand culture trees (1970).

Compared with the control (C) group the low light (-L) group showed a somewhat decreased shoot growth, but no measurable differences in root growth rate.

Shoot growth of the 'no nitrate' (-N) group retarded and stopped rather soon. Root growth in this treatment was slightly increased in the sand culture trees, but very markedly enhanced in the water culture trees (Fig. 2). Root branching was less in the latter treatment.

Effects of the different treatments on the mineral and sugar content (1970 experiments)

Partial ringing of the bark did not clearly affect the mineral and sugar content of leaves. shoots and roots of both sand culture and water culture trees.

The mineral and sugar content at harvest time of the $\mathrm{C}$ group and the $-\mathrm{L}$ group neither showed measurable differences. Reducing light by about $40 \%$ did not affect the root sugar content in a sunny period, because in that case at $60 \%$ of full sunlight $\mathrm{CO}_{2}$ is limiting for photosynthesis. Therefore, at harvest time, which was in a sunny period, no effect on the carbohydrate level was measured in the $-\mathrm{L}$ and $\mathrm{C}$ groups. On a cloudy day reducing of the light by $40 \%$ decreased photosynthesis. Therefore, the L-group consisted of smaller trees at the end of the growing season.

Table 1. The influence of different treatments on the soluble carbohydrate content of the root system (\% of dry matter).

\begin{tabular}{lll}
\hline Group & Sand culture & Water culture \\
C & 4.5 & 3.3 \\
$-\mathrm{L}$ & 4.7 & 4.0 \\
$-\mathrm{N}$ & 7.1 & 7.2 \\
\hline
\end{tabular}


The effects of the -A treatment on mineral and sugar contents consisted, as could be expected, of a general decrease of the $\mathrm{K}^{+}, \mathrm{Ca}^{++}$and $\mathrm{NO}_{3}^{-}$contents and of an enhancement of the sugar content in leaves and shoots.

A sharp $\mathrm{NO}_{3}$ drop and sugar enhancement was also found in the $-\mathrm{N}$ treatment in shoots and in roots. The content of $\mathrm{K}^{+}$and $\mathrm{Ca}++$ did not change in the $-\mathrm{N}$ treatment. Table 1 gives an idea of the effect of the different growing conditions on the sugar content of the root system.

\section{Mineral uptake measurements of the water culture trees}

The $\mathrm{K}^{+}, \mathrm{Ca}++, \mathrm{NO}_{3}^{-}$and $\mathrm{PO}_{4}^{-}$uptake measurements did not show any surprising features. In none of the groups any effect of ringing on the mineral uptake was observed. In the $-\mathrm{N}$ group especially the $\mathrm{K}^{+}$uptake was reduced. This is in agreement with experiments of Mori et al. (1958), who concluded that the absorbing process of potassium has a close relation with the growth of the shoots, which is low in the $-\mathrm{N}$ group.

A frequent root mortality of the water culture trees, which will be discussed later, was attended by a decrease in ion uptake, as could be expected. By the time root mortality occurred, shoot growth was already very low. Possibly as a result of this, the decrease in ion uptake of the roots was not reflected in a decrease of the mineral content of the leaves.

Shoot and root growth and root morphology of Cox's/M IX and Cox's/M II (1971 experiments)

Shoot growth. As can be seen in Fig. 1 the shoot growth of Cox's/M II is more vigorous than of Cox's/M IX. The new shoots of Cox's/M II were longer and heavier than those of Cox's/M IX. The average total weight of the new shoots per tree was: $1239 \mathrm{~g}$ for $\mathrm{M}$ II and $711 \mathrm{~g}$ for M IX.

Root growth and morphology. Contrary to shoot growth, lenght growth of the extension roots was clearly more rapid in Cox's/M IX (Fig. 3). The number of roots appearing on the outside of the sand column was also highest with the Cox's/M IX combinations.

However, at harvest time root weights of Cox's/M II appeared to be highest. This seeming contradiction can be explained by two differences in the morphology of the root systems of Cox's/M IX and Cox's/M II:

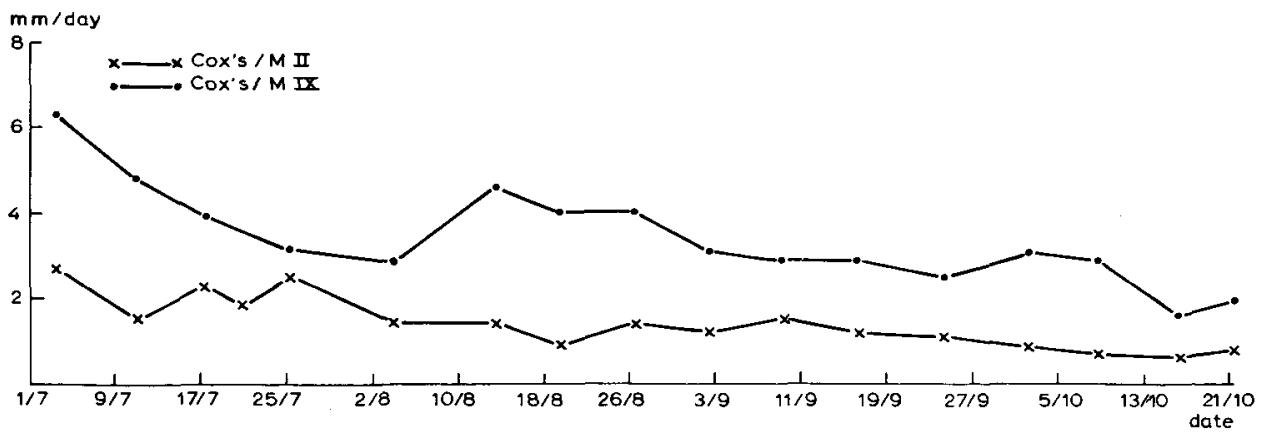

Fig. 3. Growth of the extension roots of sand culture trees (1971). 
1. About half of the extension roots of Cox's/M IX arose from the stem of the rootstock, whereas nearly all extension roots of Cox's/M II were sprouting from the older and suberized parts of the root system. Because mainly the extension roots from the stem arrived at the perspex container wall, few of the extension roots of the M II rootstock were visible.

2. The faster growth of the extension roots of the M IX rootstock was accompanied by a far less intense branching of these roots, resulting in a smaller total root weight than the Cox's/M II combination.

A comparable difference in root morphology between EM 7 and MM 111 rootstocks was described by Fugatt and Rom (1969).

\section{Appearance of Cox's disease in trees on sand culture}

In July and August 1970 Cox's disease occured in four trees of the C group, three trees of the $-\mathrm{L}$ group and (slightly) one tree of the $-\mathrm{N}$ group. Only two of these trees (one of the $\mathrm{C}$ group and one of the $-\mathrm{L}$ group) were ringed, which seems to be in agreement with the observation (Oud, 1968; Visser, 1968) that ringing partially prevents Cox's disease.

In the 1971 experiments no Cox's disease appeared in the trees on sand culture. In general 1971 proved to be a year with little Cox's disease.

Growth reactions of Cox's diseased trees. Trees with Cox's disease and trees remaining healthy did not show measurable differences in shoot and root growth in the period before the outbreak of Cox's disease. The growth of the extension roots of six trees in a period before they were affected was compared with the growth in the same period of the extension roots of six trees remaining healthy throughout. During this period, from 19 June to 6 August 1970, the average root growth of both groups was $3.8 \mathrm{~mm} /$ day and the shoot growth of both groups was 7.5 and $7.8 \mathrm{~mm} /$ day, respectively.

At the outbreak of Cox's disease the visible roots of a tree suddenly stopped growing and died. Starting from the root tip a reddish-brown region of dead root tissue extended over the whole root. At the same time the Cox's disease symptoms of the shoot became visible, while shoot growth gradually decreased.

In a number of cases some recovery of the root system was observed. New roots were visible having a normal growth rate.

Changes in mineral and sugar content of diseased trees. The most seriously diseased trees occurring in the $-\mathrm{L}$ group, the mineral and sugar contents at harvest of diseased and healthy trees of this group are shown in Table 2. Cox's disease resulted in a decreased calcium and nitrogen content of the above-ground parts, the potassium content decreasing to a less extent and only in the old leaves. The influence of Cox's disease on the mineral composition of the roots was not so clear.

Shortly after the occurrence of Cox's disease, the sugar content in the leaves of affected trees was higher than in the healthy ones. At harvest this difference had disappeared in most cases.

\section{Cox's disease and trees on water culture}

The trees on water culture did not show any symptoms of Cox's disease in the shoots. In the roots, however, many trees showed, starting in July, a sudden Cox's disease-like 
Table 2. Mineral and sugar contents (\% of dry matter) of trees affected by Cox's disease and healthy trees (-L group, 1970).

\begin{tabular}{|c|c|c|c|c|c|c|c|c|c|c|}
\hline & & \multicolumn{3}{|c|}{ Young leaves } & \multicolumn{3}{|c|}{ Old leaves } & \multicolumn{3}{|l|}{ Roots } \\
\hline & & healthy & diseased & $\begin{array}{l}\text { diseased } \\
\text { (\% of } \\
\text { healthy) }\end{array}$ & kealthy & diseased & $\begin{array}{l}\text { diseased } \\
\text { (\% of } \\
\text { healthy) }\end{array}$ & healthy & diseased & $\begin{array}{l}\text { diseased } \\
\text { (\% of } \\
\text { healthy) }\end{array}$ \\
\hline Calcium & $\begin{array}{l}\text { ringed } \\
\text { not ringed }\end{array}$ & $\begin{array}{l}0.79 \\
0.84\end{array}$ & $\begin{array}{l}0.54 \\
0.66\end{array}$ & $\begin{array}{l}68 \\
79\end{array}$ & $\begin{array}{l}1.76 \\
1.78\end{array}$ & $\begin{array}{l}1.90 \\
1.54\end{array}$ & $\begin{array}{r}108 \\
87\end{array}$ & $\begin{array}{l}0.61 \\
0.60\end{array}$ & $\begin{array}{l}0.73 \\
0.64\end{array}$ & $\begin{array}{l}120 \\
106\end{array}$ \\
\hline Potassium & $\begin{array}{l}\text { ringed } \\
\text { not ringed }\end{array}$ & $\begin{array}{l}1.98 \\
2.08\end{array}$ & $\begin{array}{l}2.00 \\
2.02\end{array}$ & $\begin{array}{r}101 \\
97\end{array}$ & $\begin{array}{l}1.97 \\
2.10\end{array}$ & $\begin{array}{l}1.54 \\
1.82\end{array}$ & $\begin{array}{l}78 \\
87\end{array}$ & $\begin{array}{l}1.10 \\
1.24\end{array}$ & $\begin{array}{l}1.12 \\
0.89\end{array}$ & $\begin{array}{r}102 \\
72\end{array}$ \\
\hline Nitrogen & $\begin{array}{l}\text { ringed } \\
\text { not ringed }\end{array}$ & $\begin{array}{l}2.41 \\
2.44\end{array}$ & $\begin{array}{l}1.86 \\
2.15\end{array}$ & $\begin{array}{l}77 \\
88\end{array}$ & $\begin{array}{l}2.28 \\
2.33\end{array}$ & $\begin{array}{l}2.09 \\
1.95\end{array}$ & $\begin{array}{l}92 \\
84\end{array}$ & $\begin{array}{l}1.92 \\
1.95\end{array}$ & $\begin{array}{l}2.01 \\
1.54\end{array}$ & $\begin{array}{r}105 \\
79\end{array}$ \\
\hline $\begin{array}{l}\text { Soluble } \\
\text { sugar }\end{array}$ & $\begin{array}{l}\text { ringed } \\
\text { not ringed }\end{array}$ & $\begin{array}{l}5.8 \\
5.8\end{array}$ & $\begin{array}{l}6.1 \\
6.6\end{array}$ & $\begin{array}{l}105 \\
114\end{array}$ & $\begin{array}{l}6.2 \\
6.3\end{array}$ & $\begin{array}{l}6.2 \\
7.2\end{array}$ & $\begin{array}{l}100 \\
114\end{array}$ & $\begin{array}{l}4.5 \\
4.1\end{array}$ & $\begin{array}{l}5.2 \\
6.3\end{array}$ & $\begin{array}{l}116 \\
159\end{array}$ \\
\hline
\end{tabular}

Table 3. Number of trees, with and without nitrogen supply, showing root mortality at different data during the growing season of 1970 .

\begin{tabular}{lrl}
\hline Date & $-\mathrm{N}$ (total 15) & $\mathrm{C}$ (total 5) \\
26 July & 2 & 0 \\
2 August & 7 & 0 \\
13 August & 11 & 1 \\
8 September & 15 & 5 \\
\hline
\end{tabular}

root mortality after a period of good root growth.

In 1970 nine trees of the $-\mathrm{N}$ group, two of the $\mathrm{C}$ group and one of the $-\mathrm{L}$ group showed this root mortality. Remarkable is that the $-\mathrm{N}$ group was most seriously affected, whereas this group showed the best root growth before.

In a few cases there was some development of new roots afterwards, but in most cases no recovery was observed.

In 1971 all the trees on water culture exibited root mortality after a period of favourable root growth. The trees without nitrogen showed the symptoms earliest (Table 3 ). In general the root system recovered more or less by development of new roots. An initial recovery could be followed by a secondary root-dying. At harvest time in October the recovery was better in the $-\mathrm{N}$ group than in the $\mathrm{C}$ group.

\section{Carbohydrate transport}

To test the hypothesis mentioned above, that root mortality was caused by a block of the carbohydrate transport at the graft union, the distribution of ${ }^{14} \mathrm{C}$-labeled sugars photosynthesized in the leaves was studied.

In Fig. 4 the radioactivity is shown of bark disks of some trees, punched above and below the graft union. The absolute number of counts per minute per bark disk showed an optimum of radioactive carbohydrates at the graft union. However, the bark is swollen at the graft union (especially in case of Cox's/M IX) and not only the con- 

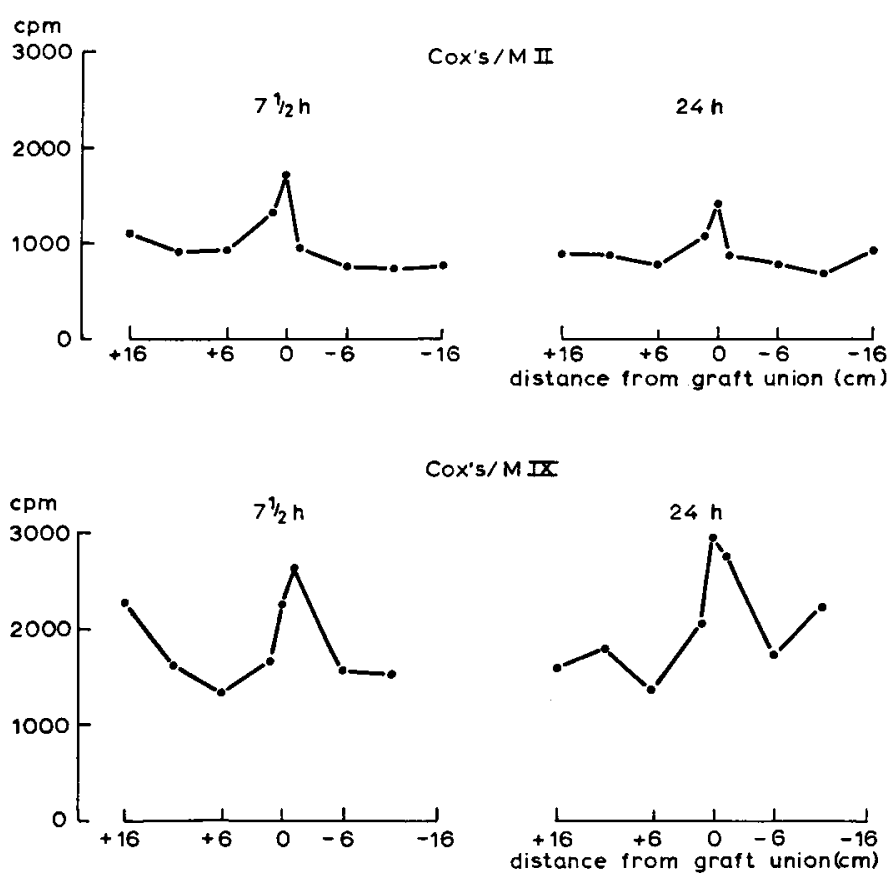

Fig. 4. Distribution of ${ }^{14} \mathrm{C}$ along the graft union zone, $71 / 2$ and 24 hours after application of ${ }^{14} \mathrm{CO}_{2}$ to a Cox's/M II tree and a Cox's/M IX tree (1971) (cpm = counts per minute).

ducting elements contained radioactivity, but also the bark parenchyma. This was demonstrated by counting the inner and outer bark separately. Hence, it can be concluded that counting the counts per minute per disk is not a good measure for the carbohydrate concentration. Since there is very little dead tissue in the young bark, calculation of the counts per minute per gramme of fresh weight of a disk may give a better indication of the carbohydrate concentration.

Fig. 5, which has been corrected in this way, shows no accumulation of carbohydrate at the graft union. No barrier for carbohydrates was found at the graft union in Cox's/ M II nor in Cox's/M IX combinations. The experiments were performed with the following number of trees:

three Cox's/M IX and two Cox's/M II on sand culture (with healthy roots). one Cox's/M IX on water culture with nitrogen (with healthy roots).

five Cox's/M IX and two Cox's/M II on water culture without nitrogen (two and one tree, respectively, with a dying or dead root system during the experiment).

Since no Cox's disease occurred in the sand culture trees, the question whether a blockage of the carbohydrate transport would possibly accompany Cox's disease in these trees is not yet answered.

In the water culture trees with a dead root system the rate of carbohydrate transport was decreased; this can be attributed to there being no sink for carbohydrates in the roots. In one tree labeling occurred at a time when the whole root system still looked healthy; however, three days later the tips of the roots were dead. The autoradiographs 

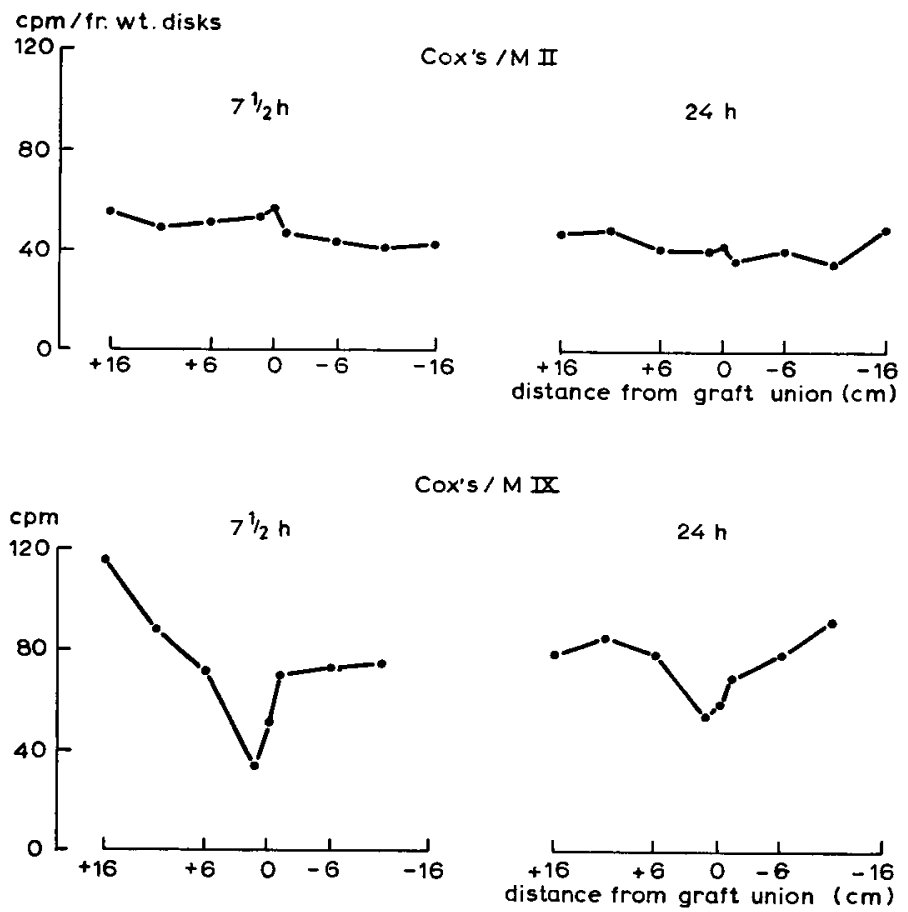

Fig. 5. Concentration of ${ }^{14} \mathrm{C}$ in the graft union zone, $71 / 2$ and 24 hours after application of ${ }^{14} \mathrm{CO}_{2}$ to a Cox's/M II tree and a Cox's /M IX tree (1971) (cpm = counts per minute).

of Fig. 6 show that in this case only the tips of the extension roots failed to accumulate label, but that lateral roots, even those very near the tip, still had carbohydrates available. The non-growing parts of the roots, through which the labeled carbohydrates are transported, showed the same grey colour on the autoradiographs as the dead root tips. This indicates that there were carbohydrates available in the root tips and that root dying was not caused by a lack of carbohydrates.

That only the periphery of the roots dies is demonstrated by development of new roots from older parts of the root system. This root initiation is shown in Fig. 7 where accumulation of labeled carbohydrates is made visible by the black spots on the autoradiograph.

\section{Discussion}

It seems clear from these and other experiments that the sudden root mortality takes a key position in the Cox's disease problem and that the above-ground symptoms of Cox's diseased trees are directly related to this root dying phenomenon.

As mentioned already these concomitant above-ground symptoms did not occur with root mortality on water culture, but the way in which the roots died was essentially the same as with the Cox's diseased sand culture trees. Whether the root morta- 

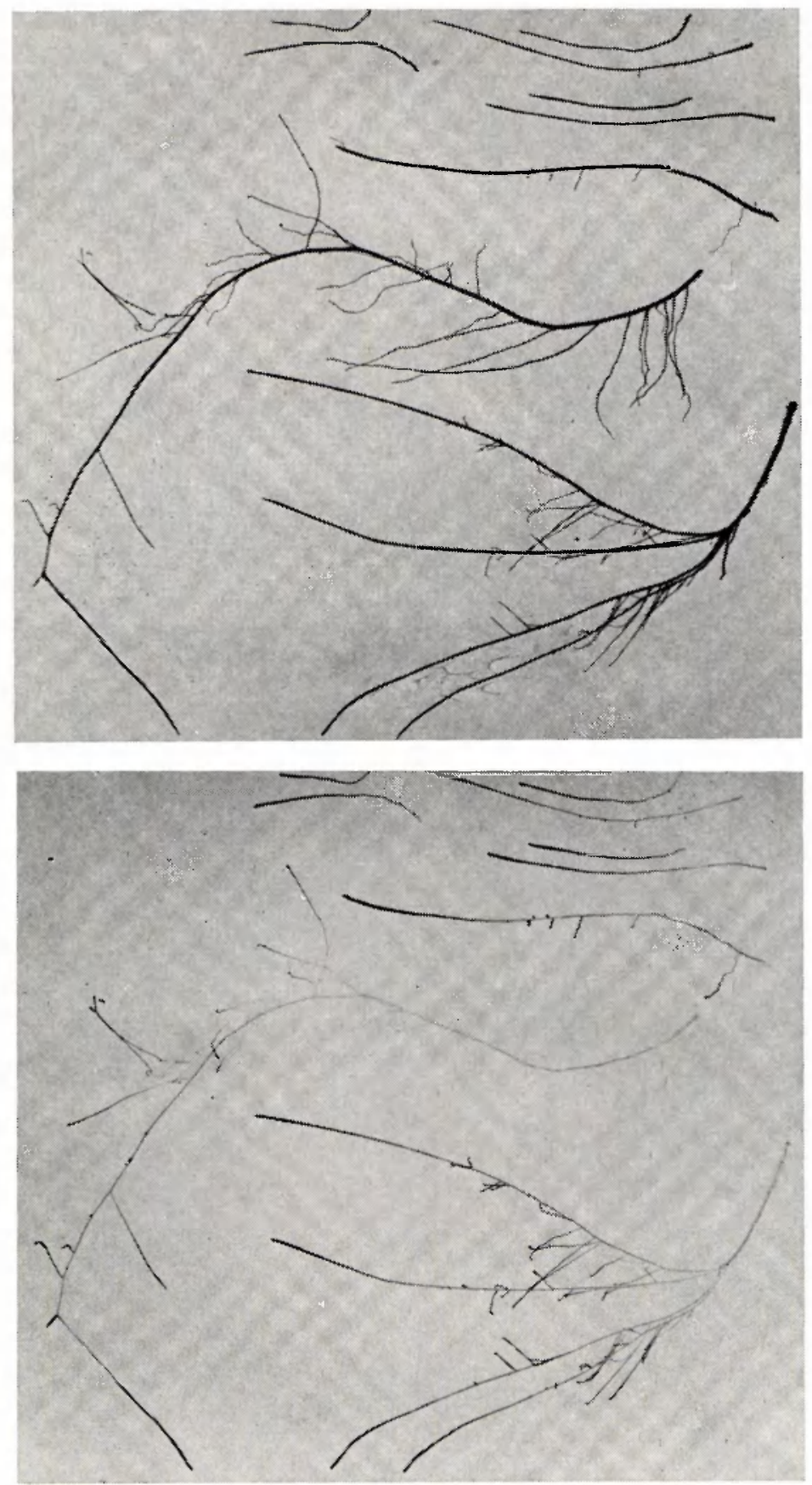

Fig. 6a. Photograph (top) and autoradiograph (bottom) of healthy extension roots. Note the accumulation of label in the growing root tips. 


\section{COX'S DISEASE IN GRAFTED COX'S ORANGE PIPPIN}
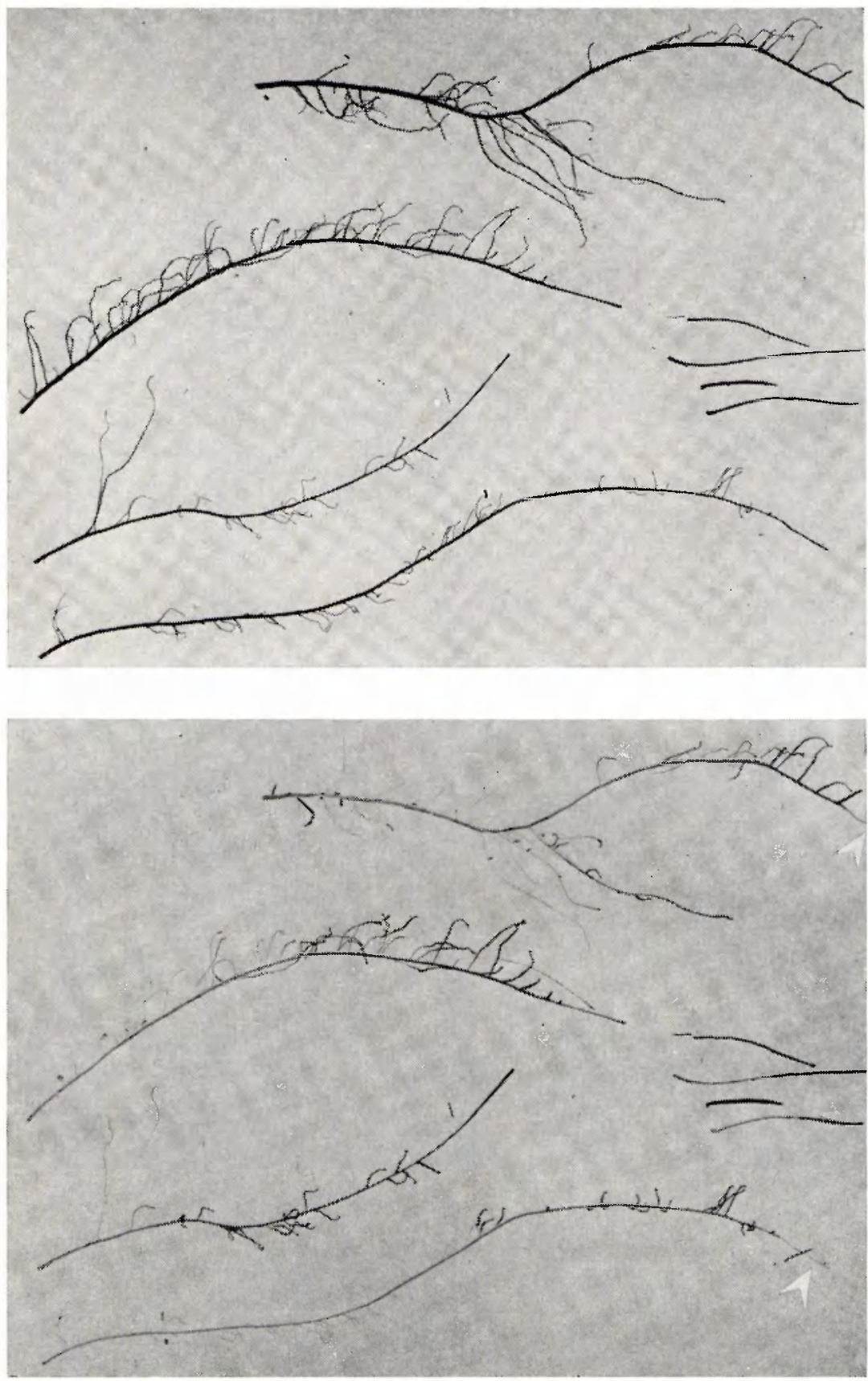

Fig. 6b. Photograph (top) and autoradiograph (bottom) of extension roots. ${ }^{14} \mathrm{CO}$, applied to the tree when root mortality started. Note the lack of label accumulation in the tips of the longest extension roots (arrows). 

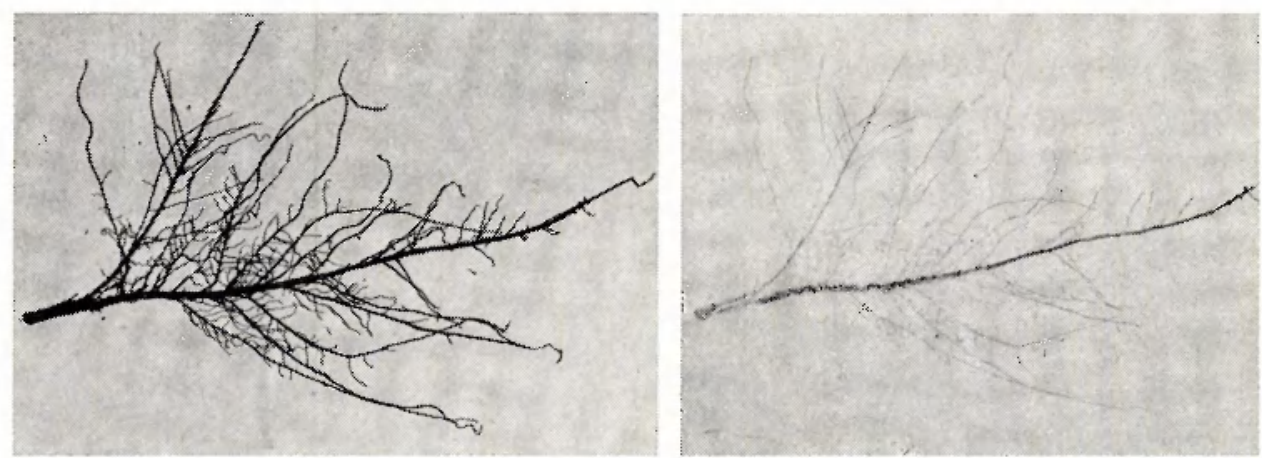

Fig. 7. Photograph (left) and autoradiograph (right) of a root affected by Cox's disease. Renewed root growth just beginning as is indicated by black spots on the autoradiograph.

lity on water culture is caused by the same factor as the Cox's disease symptoms, remains a problem. That the above-ground symptoms do not occur on water culture can be explained by the fact that the shoot growth had already almost stopped and that changes in root function no longer aftected the shoots.

In our introduction we mentioned several hypotheses to explain the root mortality phenomenon. One hypothesis was that root mortality was induced by a hampered carbohydrate transport to the roots, which was related with changes in the hormonal balance in the tree.

However, no barrier for carbohydrate transport was found at the graft union of Cox's/M IX, neither in healthy trees nor in case of root mortality of the water culture trees. The autoradiographs show that in the latter case this root mortality was not caused by a lack of carbohydrates in the root system.

The existence of a mechanical barrier is not considered as a probable alternative, according to the anatomical work of Herrero (1950) and Robitaille and Carlson (1970).

An other suggestion was that Cox's disease might be caused by a surplus of carbohydrates in the root system. This, however, is contradictory to the increase in the carbohydrate level in the root system by deprivation of nitrogen leading to an increase in growth of the individual extension roots. Although on sand culture nitrogen deprivation induced a high carbohydrate level in the roots, the number of Cox's diseased trees in this group was lower than in the $\mathrm{C}$ group.

Our morphological observations showed that a striking difference existed between the root systems of

1. sand culture Cox's/M II;

2. sand culture Cox's/M IX;

3. water culture trees (M IX as well as M II).

The roots of the sand culture Cox's/M II trees were short and branched, those of the sand culture Cox's/M IX were longer and less branched, whereas the roots of all water culture trees were very long with a low degree of branching.

Parallel to this increasing root length and decreasing root branching an increasing susceptibility for root mortality is observed. Some authors, discussing the mechanism of dwarfing rootstocks (Gur and Samihe, 1968; Miller, 1965), suggest that the vigour of an apple rootstock is negatively correlated with the IAA oxydizing capacity of leaf or bark extract. This means that the auxin level in dwarfing rootstocks is low, which 
agrees with the observed root morphology of Cox's/M IX compared with Cox's/M II. M IX trees with a greater dwarfing capacity have a longer and less branched root system. That root morphology and elongation are affected by auxins follows from the work of Richardson (1957) and other workers.

The long and unbranched morphology of the roots on water culture suggests a lower auxin content of these roots, when compared to Cox's/M IX roots on sand culture. These relations between root morphology and auxin level on the one hand, and between root morphology and root mortality on the other hand, point to a possible relation between auxin level and root mortality. This suggestion is supported by the following considerations:

1. Cox's disease is occurring when the shoots stop growing.

This growth stop is accompanied by a diminished auxin production by the top meristem of the shoots and therefore by a lower auxin level in the tree.

2. Removal of growing fruit increases the susceptibility for Cox's disease. The tree is then deprived of auxins produced by the ripening seeds.

3 . The root mortality symptoms of water culture trees appear earlier when nitrogen is omitted from the nutrient solution. Experiments of Bosemark (1954) indicate that lack of nitrogen is accompanied by a lower auxin level in the roots.

4. The number of diseased trees can be diminished if a partial ring is applied to the bark. The best results are obtained if in the next year a new ring is applied under the old one. This indicates that a partial ring does not act as a barrier, but as a source of a substance preventing Cox's disease. This may be auxin produced by the wound cambium.

Summarizing we offer the tentative conclusion that Cox's disease is connected with a low auxin level in the root system. In literature it is supported that a low auxin level in the root system causes dwarfing. These two suppositions lead to the statement that Cox's disease may be inherent to dwarfing rootstocks.

The purpose of experiments to be done in 1972 is a further examination of the relation between auxins and Cox's disease.

\section{Acknowledgments}

The experiments were performed in co-operation with the IJsselmeer Polders Development and Settlement Authority at Kampen, where most of the chemical analyses were done. The radioactivity measurements were done at the Centre for Plant Physiological Research at Wageningen. Special thanks are due to Mr J. Visser and Mr P. Slager for discussing the problem at several stages of the investigation and assisting during the experiments and to Prof. Dr R. Brouwer for discussing the results and for his critical reading of the manuscript.

\section{References}

Bosemark, N. O., 1954. The influence of nitrogen on root development. Physiol. Plant. 7: 497-502.

Bruno, G. A. \& J. E. Christian, 1961. Determination of Carbon-14 in aqueous bicarbonate solutions by liquid scintillation counting techniques. Application to biological fluids. Anal. Chem. 33 : 1216.

Das, A., P. Oud \& A. Schellekens, 1967. Inleiding en verslag onderzoek Cox's-ziekte in de Noordoostpolder in 1966. Wageningen, Rijkstuinbouwconsulentschap voor bodemaangelegenheden.

Dickson, A. G. \& E. W. Samuels, 1956. The mechanism of controlled growth of dwarf apple trees. J. Arnold Arboretum 37: 307-313. 
Fugatt, B. L. \& R. C. Rom, 1969. Rooting behaviour of three clonal apple stocks. Arkansas Farm Res. 18: 8.

Gur, A. \& R. M. Samish, 1968. The role of auxins and auxin destruction in the vigor effect induced by various apple rootstocks. Beiträge zur Biologie der Pflanzen (Berlin) 45: 91-111.

Herrero, J., 1950. Studies of compatible and incompatible graft combinations with special reference to hardy fruit trees. J. hort. Sci. 26: 186-237.

Miller, S. R., 1965. Growth inhibition produced by leaf extracts from size controlling apple rootstocks. Can. J. Pl. Sci. 45: 519-524.

Mori, H., T. Yamazahi \& I. Abe, 1958. On the potassium nutrition of apple trees. Potassium Symposium (Tokyo, 1958). International Potass. Institute, Bern.

Oud, P., 1968a. Nieuwe inzichten betreffende de Cox's ziekte. Fruitteelt 58: 1172-1174.

Oud, P., 1968b. Maatregelen ter voorkoming van de Cox's ziekte. Fruitteelt 58: 1194-1196.

Richardson, S. D., 1957. Studies of root growth in Acer saccharinum. IV. Further effects of the shoot system on root growth. Proc. K. ned. Akad. Wet. C 60: 624-629.

Robitaille, H. A. \& R. F. Carlson, 1970. Graft union behaviour of certain species of Malus and Prunus. J. Am. Soc. hort. Sci. 95: 131-134.

Stigter, H. C. M. de, 1961. Translocation of ${ }^{14} \mathrm{C}$ photosynthates in the graft Muskmelon / Cucurbita ficifolia. Acta bot. neerl. 10: 466-473.

Stigter, H. C. M. de, 1971. Some aspects of the physiological functioning of the graft Muskmelon / Cucurbita ficifolia. IV. Observations on a Cucurbita Isograft 'Model', and effects of localized stem cooling. Z. PflPhysiol. 65: 296-308.

Visser, J., 1968. De invloed van het bodemmileu op het voorkomen van Cox's ziekte in de IJsselmeerpolders. Flevoberichten (Zwolle) 56.

Visser, J., J. Th. Locher \& R. Brouwer, 1971. Effects of aeration and mineral supply on growth and mineral content of shoots and roots of apple trees (var. Golden Delicious on M IX). Neth. J. agric. Sci. 19: 125-137.

Wegner, L. A. \& H. Winkelmann, 1970. Die Verbrennung ${ }^{14} \mathrm{C}$ oder ${ }^{3} \mathrm{H}$ haltiger Proben als Vorstufe zur L.S.-Messung. Erste Erfolge mit einem neuen Automaten. Atompraxis 16: 19-25. 